\title{
EFFECT OF INTRA-UTERINE PLATELET-RICH PLASMA INFUSION IN PATIENTS WITH THIN ENDOMETRIUM PREPARED FOR FROZEN EMBRYO TRANSFER
}

Ashraf Hanie Abd El-Rahman, Sherif Salah Elsayed Gaafar, Dalia Abd Elmoaty Elneily*, Sarah Helmy Abd El-Wahab Zahra

Department of Obstetrics and Gynecology, Faculty of Medicine, University of Alexandria, Department of Clinical and Chemical Pathology*, Faculty of Medicine, University of Alexandria

\section{INTRODUCTION}

Endometrium is one of the main factors in implantation and pregnancy. Pregnancy rate thickness. Most patients with the standard medical therapies reach the desired endometrial thickness (EMT) and small numbers of patients fail to reach the minimum EMT. The empirical preference for EMT for implantation is $>7 \mathrm{~mm}$.

Intrauterine infusion of platelet-rich plasma (PRP) is a new approach that has been suggested for the treatment of thin endometrium as it is widely used in various fields. PRP is blood plasma prepared from fresh whole blood that has been enriched with platelets. It contains several growth factors that stimulate proliferation and growth.

\section{AIM OF THE WORK}

Aim of this work was to evaluate the effect of intra-uterine infusion of platelet-rich plasma (PRP) in frozen embryo transfer cycles: effect on the endometrial thickness and clinical pregnancy rates in women with refractory thin endometrium.

\section{SUBJECT AND METHODS}

Women who had a history of failed IVF cycles and refractory thin endometrium were enrolled in this study. The main inclusion criteria were EMT of $\leq 7 \mathrm{~mm}$ after more than 2 cycles of previous medical therapy for increasing the EMT. 26 women were enrolled in this study. The subjects were treated with intrauterine infusion of autologous PRP in this study. The subjects were treated with intrauterine infusion of autologous PRP
once or twice according to ultrasonographic measurements from menstrual cycle day 9 once or twice according to ultrasonographic measurements from menstrual cycle day 9
of their frozen-thawed embryo transfer (FET) cycle, and ET was performed 3 days after the final autologous PRP infusion. PRP was injected into the uterine cavity using IUI catheter within $1 \mathrm{~h}$ from completion of PRP preparation

24 patients underwent FET, and 2 patients had still thin endometrium, so their cycles were cancelled. Ultrasonography was performed to measure the EMT on MCD 2, MCD 9 and every autologous PRP administration day.

The serum $\beta$-hCG level was measured from peripheral blood 2 weeks after ET.

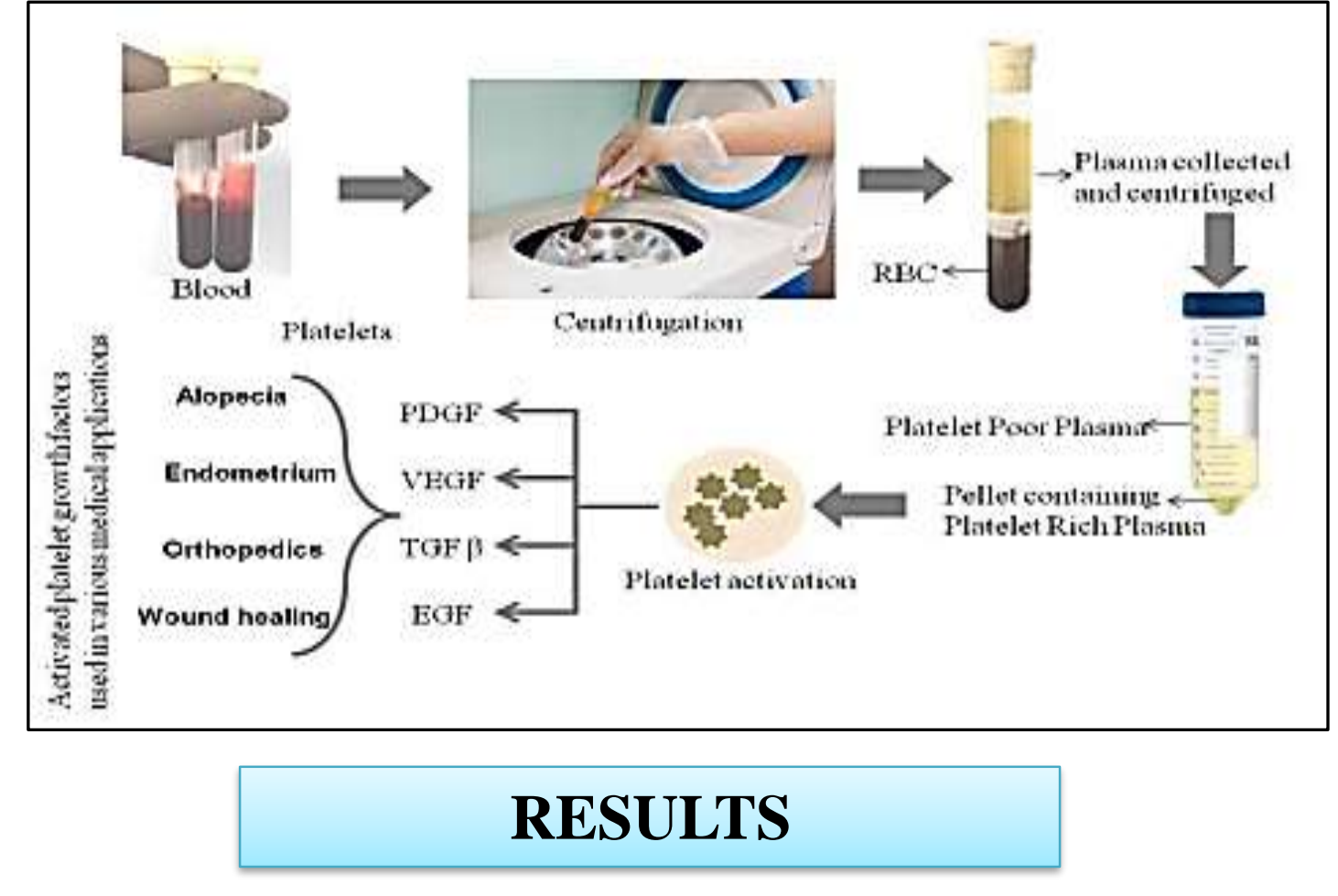

This study showed that pre-PRP EMT ranged from 5.40 to $6.80 \mathrm{~mm}$. While post-PRP EMT ranged from 5.50 to $8.30 \mathrm{~mm}$

There was a statistically significant increase in EMT after PRP infusion.

Clinical pregnancy rate was $45.8 \%$, ongoing pregnancy rate was 37.5 $\%$, and no one $(0 \%)$ had ectopic pregnancy.

Table 1: Comparison between pre-PRP and post-PRP according to EMT

\begin{tabular}{|l|l|l|}
\hline \multicolumn{1}{|c|}{ EMT (mm) } & \multicolumn{1}{c|}{ Pre-PRP } & \multicolumn{1}{c|}{ Post-PRP } \\
\hline Min. - Max. & $5.40-6.80$ & $5.50-8.30$ \\
\hline Mean \pm SD. & $6.15 \pm 0.38$ & $7.49 \pm 0.61$ \\
\hline Median (IQR) & $6.20(5.90-6.50)$ & $7.50(7.30-7.90)$ \\
\hline
\end{tabular}

Table 2: Other studies that showed effect of intrauterine infusion of PRP in thin endometrium

\begin{tabular}{|c|c|c|}
\hline $\begin{array}{c}\text { Author, } \\
\text { year }\end{array}$ & Population & Reproductive outcomes \\
\hline $\begin{array}{l}\text { Eftekhar } \\
\text { et al. (2018) }\end{array}$ & $\begin{array}{l}\text { Women with poor endometrial response } \\
\text { to standard hormonal preparation } \\
\text { (ET }<7 \mathrm{~mm} \text { ) in the 13th day of FET cycle. }\end{array}$ & $\begin{array}{l}\text { PRP higher ET }(0.001) \text {, implantation } \\
(\mathrm{P}=0.002) \text { and pregnancy rate }(\mathrm{P}=0.044) .\end{array}$ \\
\hline $\begin{array}{l}\text { Wang } \\
\text { et al. (2018) }\end{array}$ & $\begin{array}{l}\text { Patients with recurrent implantation failure } \\
\text { due to suboptimal endometrial pattern, } \\
\text { women with } \geq 2 \text { canceled cycles } \\
\text { due to thin endometrial lining. }\end{array}$ & $\begin{array}{l}\text { Successful endometrial expansion after PRF } \\
(5.55 \pm 0.71 \mathrm{~mm} \text { vs } 7.82 \pm 1.04 \mathrm{~mm} \\
\mathrm{P}<0.001 \text {, for pre- and post }- \text { PRI } \\
\text { respectively). Pregnancy was positive in } 12 \\
\text { cases after PRP infusion }(60 \%) .\end{array}$ \\
\hline $\begin{array}{l}\text { Kim } \\
\text { et al. (2019) }\end{array}$ & $\begin{array}{l}\text { Patients with history of } \geq 2 \text { failed IVF } \\
\text { cycles and refractory thin endometrium } \\
(<7 \mathrm{~mm}) \text {. }\end{array}$ & $\begin{array}{l}\text { PRP improved implantation, pregnancy anc } \\
\text { live birth rates in comparison to thei } \\
\text { previous cycles. }\end{array}$ \\
\hline $\begin{array}{l}\text { Chang } \\
\text { et al. (2019) }\end{array}$ & $\begin{array}{l}\text { Patients with thin endometrium }<7 \mathrm{~mm} \\
\text { and prior canceled FET. }\end{array}$ & $\begin{array}{l}\text { PRP had higher ET and lower ancellatior } \\
\text { rate. } \\
\text { Higher implantation and clinical pregnancy } \\
\text { rate in favor of PRP (27.94\% vs } 11.67 \% \text { ) } \\
\mathrm{P}<.05 ; 44.12 \% \text { vs } 20 \%, \mathrm{P}<.05 \text {, respectively) }\end{array}$ \\
\hline
\end{tabular}

\section{CONCLUSION}

- PRP therapy is an effective therapy in patients with refractory thin endometrium. The endometrial thickness and the clinical pregnancy rates were statistically significant increase with intra-uterine infusion of PRP.

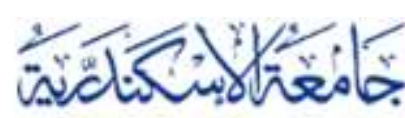
ALEANDRIA

2021@Alexandria Faculty of Medicine CC-BY-NC 